\title{
Prevalence and associated risk factors of anaemia among women attending antenatal and post-natal clinics at a public health facility in Ghana
}

Philip Kofie ${ }^{1 *}$ D, Elvis E. Tarkang², Emmanuel Manu², Hubert Amu², Martin Amogre Ayanore ${ }^{3}$, Fortress Yayra Aku', Joyce Komesuor ${ }^{2}$, Martin Adjuik', Fred Binka ${ }^{1}$ and Margaret Kweku'

\begin{abstract}
Background: Anaemia among pregnant women and post-partum mothers is a public health challenge in Ghana, especially in the Volta Region. While literature abounds on anaemia among pregnant women, the same cannot be said for anaemia among post-partum mothers in the region. This study, therefore, examined the prevalence and associated risk factors of anaemia among women attending antenatal care and post-natal care.

Methods: This descriptive cross-sectional survey recruited 409 pregnant women and 194 post-natal mothers attending antenatal and post-natal care, at the Hohoe Municipal Hospital. Background characteristics were collected using a semistructured questionnaire, blood samples were analysed for the presence of anaemia and malaria parasitaemia and folders were reviewed for estimated blood loss.

Results: We found the prevalence of anaemia among pregnant women and post-partum mothers to be 33 and $16 \%$ respectively. Higher malaria parasitaemia (2\%) was found in pregnant women compared with postpartum mothers (1\%). We found that $4 \%$ of post-partum mothers had abnormal blood loss (301mls$500 \mathrm{mls}$ ) whereas $5 \%$ of them had postpartum haemorrhage $(>500 \mathrm{mls})$ during child birth. A univariate logistics regression of anaemia status on some risk factors in pregnant women showed no significant association between anaemia and any of the risk factors. Among post-partum mothers, only mothers' age was statistically significant in the univariate analysis $[C O R=0.27(95 \% \mathrm{Cl}: 0.103,0.72) ; 0.008]$. Mothers aged 20-29 were $73 \%$ less likely to be anaemic.

Conclusion: The prevalence of anaemia among pregnant women found in this study points to a situation of moderate public health problem according to WHO cut-off values for the public health significance of anaemia. Strategies should therefore be put in place to encourage thorough health education and promotion programmes among both pregnant and post-partum women.
\end{abstract}

Keywords: Anaemia, Pregnant women, Post-partum mothers, Antenatal care, Post-natal care, Hohoe municipality, Hohoe municipal hospital, Ghana

\footnotetext{
* Correspondence: niiquophie@gmail.com

${ }^{1}$ Department of Epidemiology and Biostatistics, School of Public Health,

University of Health and Allied Sciences, PMB 31, Ho, Volta Region, Ghana

Full list of author information is available at the end of the article
}

(c) The Author(s). 2019 Open Access This article is distributed under the terms of the Creative Commons Attribution 4.0 International License (http://creativecommons.org/licenses/by/4.0/), which permits unrestricted use, distribution, and reproduction in any medium, provided you give appropriate credit to the original author(s) and the source, provide a link to the Creative Commons license, and indicate if changes were made. The Creative Commons Public Domain Dedication waiver (http://creativecommons.org/publicdomain/zero/1.0/) applies to the data made available in this article, unless otherwise stated. 


\section{Background}

Anaemia, referred to as low level of haemoglobin $(\mathrm{Hb})$ in the blood, is a global public health problem that affects low, middle, and high-income countries, with adverse effects on the health of populations [1]. Anaemia is defined as $\mathrm{Hb}$ level lower than $11.0 \mathrm{~g} / \mathrm{dl}$ $(\mathrm{Hb}<11.0 \mathrm{~g} / \mathrm{dl})$ in pregnant women [2], and $\mathrm{Hb}$ level lower than $10.0 \mathrm{~g} / \mathrm{dl}(\mathrm{Hb}<10.0 \mathrm{~g} / \mathrm{dl})$ in postpartum mothers [3]. Though the condition affects males, pregnant and non-pregnant women as well as children are most vulnerable $[4,5]$.

Anaemia is multifactorial in aetiology but mainly caused by iron-deficiency [6, 7]. Anaemia can be dangerous to the health of both a pregnant woman and her baby, if left untreated [8] as it increases the risk of maternal and child mortality and also has a significant negative effect on both the cognitive and physical development of the child $[4,9]$.

Global anaemia prevalence is estimated by the WHO to be $38 \%$ in pregnant women and $29 \%$ in all women of reproductive age [1]. According to WHO cut of points for significance of anaemia, prevalence of $\geq 40 \%$ is considered a severe public health problem [1]. In Africa, a 2013 cross-sectional study conducted among 384 pregnant women in Northwest Ethiopia found the prevalence of anaemia to be $22 \%$ [10]. A 2016 study conducted by Bekele, Tilahun and Mekuria [11] among 332 pregnant women in the same country, however, found anaemia prevalence to be $33 \%$, an indication that the problem was on the ascendency. Furthermore, a cross-sectional secondary data analysis on anaemia prevalence among post-partum mothers in the same country found $22 \%$ prevalence rate [12], lower than the prevalence rates among pregnant women $[10,11]$.

In Ghana, a report by the Family Health Division (FHD) of the Ghana Health Service (GHS), showed that anaemia among pregnant women at first antenatal clinic visit marginally increased by $1 \%$ in the year 2015 as compared to the previous year [13]. The report further stated that the prevalence of anaemia in pregnant women at 36 weeks of pregnancy also increased marginally from the year 2015 to 2016 . The Volta Region has been identified as the region with the highest prevalence (49\%) of anaemia among women in their reproductive age (15-49 years) in the country [14]. As such, it is the region with the highest proportion of antenatal clients having anaemia over the period of 2014 to 2016 , with prevalence rates of 46, 46, and 47\% in 2014, 2015 and 2016 respectively [13].

The FHD reported anaemia in the region at the time of antenatal clinic registration and at 36 weeks of pregnancy to be 46 and 32\% respectively in 2014;
46 and 26\% respectively in 2015; and 47 and $27 \%$ respectively in 2016 [13]. Although there is provision of iron and folic acid to postnatal mothers from the day of delivery up to the sixth week in the country [13], anaemia remains the leading cause of hospital admissions and maternal deaths in the Volta Region $[15,16,17]$. In the Hohoe Municipality where the present study was conducted, the prevalence of anaemia in pregnant women attending antenatal care was reported to be $60.3 \%$ [18], with $64 \%$ among new registrants and 58\% among those with multiple visits. This prevalence is higher than the regional prevalence of $49 \%$.

Despite the available evidence on anaemia and its consequences, there has not been any study on postpartum anaemia in the Volta Region of Ghana. Postpartum period, characterized by some physiological losses due to pregnancy and labour is a very critical period which needs a lot of attention. The paucity of information on anaemia status of this vulnerable group in the region possess as a weakness of health system as no or little information is available to guide health professionals in ensuring good health of postpartum mothers. We, therefore, examined the prevalence and associated risk factors of anaemia among women attending antenatal and post-natal clinics at the Hohoe Municipal Hospital so that a holistic approach in addressing maternal anaemia in the municipality, the region, and the country as a whole could be adopted.

\section{Methods}

\section{Setting}

The Hohoe Municipality is one of the twenty-five administrative districts/municipalities in the Volta Region [19]. The Municipality lies within the middle zone of the region and shares boarders on the East with the Republic of Togo, on the Southwest with Kpando Municipality, Northwest with Biakoye District, on the North with Jasikan District, and on the South with Afadzato South District [19]. The Municipality consists of 102 communities with a population of 167,016 people and a population density of 196.0 persons per square kilometres [19].

\section{Study design}

This descriptive cross-sectional study recruited 409 pregnant women (6 weeks to 36 weeks of gestation) and 194 postnatal mothers (6 weeks post) of ANC and PNC centres of Hohoe Municipal Hospital for the period March 2017. 


\section{Procedures}

We estimated the sample sizes for pregnant women using the regional prevalence of $47 \%$ [13] and $14 \%$ for post-partum mothers [20], using the Cochrane formula [21]. Assuming z-statistic for 95\% level of confidence and a $5 \%$ margin of error, the appropriate minimum sample size was estimated for the study.

Adjusting for a non-response rate of 5\%, a total sample size of 402 was reached for pregnant women and 194 for post-partum mothers.

During data collection, thirty (30) pregnant women were randomly selected each day by balloting without replacement method. The balloting method allowed consented participants to either pick "Yes" or "No" of folded pieces that were placed in a container and thoroughly shaken to ensure randomization. Data was collected from participants who picked "Yes". This was repeated until the desired sample size was attained. The same sampling procedure was done with regards to the postnatal mothers. Data were collected at PNC clinic and post-delivery wards of the Hospital.

With the aid of trained research assistants, data on socio-demographic characteristics and risk factors associated with anaemia (independent variables) in both pregnant and postpartum mothers were collected using a pre-tested semi-structured questionnaire. Haemoglobin concentration $(\mathrm{Hb})$ were determined by fingerpricked blood test samples of participants using URIT12 Haemoglobin photometer (URIT Medical Electronics Co., LTD, China). Anaemia was defined as $\mathrm{Hb}$ level lower than $11.0 \mathrm{~g} / \mathrm{dl}(\mathrm{Hb}<11.0 \mathrm{~g} / \mathrm{dl})$ in pregnant women [2] and $\mathrm{Hb}$ level lower than $10.0 \mathrm{~g} / \mathrm{dl}$ in postpartum mothers $(\mathrm{Hb}<10.0 \mathrm{~g} / \mathrm{dl})$ [3]. Capillary blood sampling from the finger was used because it provides a reliable and suitable alternative for sampling blood in the clinical and field settings [22-24].

Estimated blood loss data of postpartum mothers were obtained from the maternal delivery records. Blood loss volume of $\leq 300 \mathrm{ml}$ was considered normal and $>300$ $\mathrm{ml}-500 \mathrm{ml}$ was considered abnormal. Blood loss volume ( $>500 \mathrm{mls}$ ) was considered postpartum haemorrhage (PPH) [21].

Parasitaemia in blood samples were detected using standardized blood film and staining procedures [25]. Three drops of blood were placed on a clean, dust free and dry frosted microscopic slide for thick blood film. Also a drop of blood was placed on the side of the thick film for the preparation of a thin film. A unique Identification number (ID) for each participant and date were written on each slide for easy identification. The slides were air dried and packed into slide boxes and transported to the SPH, UHAS laboratory. The dried slides were stained with $1 \%$ Giemsa stain for about $25-30 \mathrm{~min}$. Buffered water $(\mathrm{pH}=7)$ was used to rinse the stained slides. The prepared slides were examined under oil immersion with a light microscope (ocular magnification $\times 100$ ). The thick film was used for the quantification of the malaria parasites while the thin film was used for identifying the malaria species. Parasite densities were estimated by counting the number of parasites per 200 white blood cells (WBCs) in a thick film by two microscopists. Counts of gametocyte were taken against 500 white blood cells in determining gametocyte density per microliter of blood.

Light microscope was used to read the slides, a sample was considered negative only after 200 high power fields have been read. Parasite counts were converted to parasite per $\mu 1$, with the assumption that there is an average of 8000 leucocytes per $\mu 1$ of blood. In cases where there was a 50\% discrepancy between parasite counts or when there was a discrepancy qualitatively (negative versus positive), a third microscopist read the slide and his reading was final and was used in the analysis of parasite density. All slides were stored in appropriately labelled slide boxes and kept at the laboratory. As part of the quality control monitoring, randomly selected stained slides from each batch of slides were given to an independent microscopist at the Municipal hospital for the determination of the sensitivity and specificity of the readers. $\mathrm{Hb}$ readings were quality controlled by trained laboratory scientists from the School of Public Health (SPH) of the University of Health and Allied Sciences (UHAS), research laboratory throughout the study period.

\section{Ethical issues}

This study was conducted in accordance with accepted principles on ethics in human experimentation and international conference on Harmonization/Good Clinical Practice (ICH/GCP). Ethical approval for the study was obtained from the Ethics Review Committee (ERC) of the University of Health and Allied Sciences (UHAS) with Ethical Approval number UHASERC A.6 [6] 17-18. Permission was sought from the Hohoe Municipal Hospital before the commencement of the study. Written informed consent was obtained from participants on standard consent form before they were included in the study.

\section{Data analysis}

The data were entered into EpiData version 3.0 and exported to Stata version 14.1 for analysis. Descriptive statistics, frequencies and percentages were used for categorical variables. Normality was determined for continuous variables such Age, $\mathrm{Hb}$, gravidity, parity 
and family size. Mean \pm SD was determined for continuous variables using t-test. Chi-square test was used to determine association between independent variables (socio-demographic characteristics and risk factors) and the dependent variable (anaemia status). A univariate logistic regression was used to determine the strength of the association between the independent and dependent variable. The dependent variable considered in the univariate logistic regression was anaemia status. However, a multivariable logistic regression could not be used because only one variable in the univariate logistic regression showed a statistically significant association with the dependent variable (Anaemia status). Therefore, there was no need to use a multivariable logistic regression. A $p$-value less than 0.05 was considered statistically significant at $95 \%$ Confidence Interval $(\mathrm{CI})$.

\section{Results}

\section{Socio-demographic characteristics of respondents}

Table 1 shows the background characteristics of the respondents, for both ANC and PNC attendees. The continuous variables ag and $\mathrm{Hb}$ were normally distributed. Out of the 409 pregnant women surveyed, majority (49\%) of them were aged 20-29 years. The mean age of the pregnant women was $28 \pm 7$ years. Most, (83\%) of the pregnant women were married and had at least Junior Secondary education (65\%). With regards to occupation, about two-fifth of the pregnant women $(38 \%)$ were involved in trading at the time of the study. Majority (71\%) of them were Ewes, with Christianity being the dominant religion (85\%). More than half (54\%) of the pregnant women were at least, pregnant for the second time (Gravida 2 ) in their lives at the time of the survey. A little less than half of (41\%) respondents had at least one or two children. More than half (77\%) of pregnant women were in their 3rd trimester.

\section{Prevalence of anaemia and malaria among pregnant and postpartum women attending ANC and PNC clinics}

Out of the total number (409) of pregnant women whose $\mathrm{Hb}$ levels were measured, $33 \%$ them were found to be anaemic $(\mathrm{Hb}<11.0 \mathrm{~g} / \mathrm{dl})$ with a mean $\mathrm{Hb}$ of $9.72 \pm 0.97$. Out of the mothers (194) attending PNC, $16 \%$ of them were anaemic $(\mathrm{Hb}<10 \mathrm{~g} / \mathrm{dl})$. The mean $\mathrm{Hb}$ recorded for the postpartum mothers was $7.76 \pm 1.68$ (Fig. 1). The prevalence of malaria parasitaemia by microscopy was 2 and $1 \%$ for pregnant women and postpartum mothers respectively (Fig. 1).
Table 1 Background characteristics of women attending ANC and PNC clinics $[N=603]$

\begin{tabular}{|c|c|c|}
\hline Characteristic & ANC $[N=409]$ & $\mathrm{PNC}[N=194]$ \\
\hline Mean Age (SD) & $28 \pm 6$ & $27 \pm 7$ \\
\hline \multicolumn{3}{|l|}{ Age group (in years) } \\
\hline$<20$ & $49(12)$ & $33(17)$ \\
\hline $20-29$ & $208(51)$ & $96(49)$ \\
\hline $30-39$ & $138(34)$ & $58(29)$ \\
\hline $40>$ & $14(3)$ & $10(5)$ \\
\hline \multicolumn{3}{|l|}{ Marital Status } \\
\hline Single & $68(17)$ & $41(21)$ \\
\hline Married & $341(83)$ & $156(79)$ \\
\hline \multicolumn{3}{|l|}{ Educational Level } \\
\hline None & $30(7)$ & $13(7)$ \\
\hline Primary & $71(17)$ & $37(19)$ \\
\hline Secondary (JHS/SHS) & $267(65)$ & $126(64)$ \\
\hline Tertiary & $41(10)$ & $21(10)$ \\
\hline \multicolumn{3}{|l|}{ Occupation } \\
\hline Unemployed & $102(25)$ & $53(27)$ \\
\hline Artisan & $103(25)$ & $49(25)$ \\
\hline Civil servant & $37(9)$ & $17(9)$ \\
\hline Farming & $15(3)$ & $15(7)$ \\
\hline Trading & $152(38)$ & $63(32)$ \\
\hline \multicolumn{3}{|l|}{ Religion } \\
\hline Christianity & $346(85)$ & $167(85)$ \\
\hline Muslim & $63(15)$ & $30(15)$ \\
\hline \multicolumn{3}{|l|}{ Tribe } \\
\hline Ewe & $291(71)$ & $148(75)$ \\
\hline Others & $118(29)$ & $49(25)$ \\
\hline Mean Haemoglobin level (g/dl) & $11.78 \pm 1.93$ & $11.82 \pm 2.48$ \\
\hline \multicolumn{3}{|l|}{ Gravidity } \\
\hline $1-2$ & $219(54)$ & $116(59)$ \\
\hline $3-5$ & $168(41)$ & $66(34)$ \\
\hline $6 \leq$ & $22(5)$ & $15(7)$ \\
\hline \multicolumn{3}{|l|}{ Parity } \\
\hline None (Nulliparous) & $144(35)$ & - \\
\hline $1-2$ & $168(41)$ & $118(60)$ \\
\hline $3+$ & $97(24)$ & $79(40)$ \\
\hline \multicolumn{3}{|l|}{ Gestational age } \\
\hline 1st trimester & $58(14)$ & - \\
\hline 2nd trimester & $37(9)$ & - \\
\hline 3rd trimester & $314(77)$ & - \\
\hline
\end{tabular}




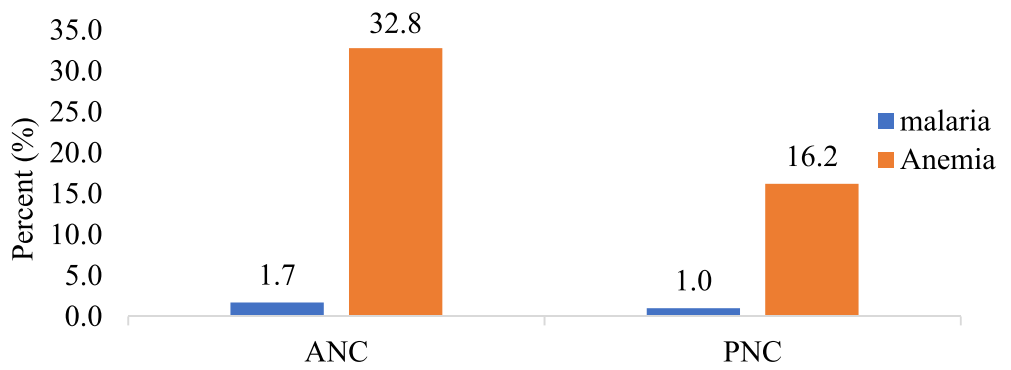

Fig. 1 Prevalence of malaria and anaemia in pregnant and post-partum women

\section{Prevalence of anaemia and malaria among pregnant women by gestational period}

The prevalence of anaemia among pregnant women by gestational period was highest (38\%) among women in their 2nd trimester and lowest (31\%) among those in their 1st trimester (Fig. 2). Malaria prevalence followed similar pattern as anaemia, 5\% for pregnant women in their 2 nd trimester, $1.6 \%$ in the 3rd trimester and none in the 1 st trimester.

\section{Estimated blood loss of postpartum mothers}

Out of the total number (177) of mothers whose records were retrieved for the estimation of blood loss (Fig. 3), majority (92\%) had normal blood losses $(\leq 300 \mathrm{ml}),(4 \%)$ of them had abnormal blood loss (301 ml-500mls) and (5\%) had postpartum haemorrhage $(>500 \mathrm{mls})$.

\section{Association between Anaemia and some risk factors among pregnant women}

Table 2 shows the results of the univariate logistic regression of anaemia status (dependent variable) on some risk factors, namely age group, marital status, religion, ethnicity, occupation, gravidity, parity, blood film and gestational age of the mother. There was no significant association between anaemia status and any of the risk factors in a univariate analysis, no further multivariable logistic regression was necessary.

\section{Association between Anaemia and some risk factors among post-partum mothers}

Table 3 shows the results of the univariate logistic regression of anaemia status on some risk factors, namely age group, marital status, religion, ethnicity, occupation, parity, gravidity and blood film of the mother. Only mothers' age was statistically significant in the univariate analysis. [COR $=0.27$ (95\% CI:0.103, 0.72);0.008]. Mothers aged 20-29 were 73\% less likely to be anaemic compared to those who were aged $40+$.

\section{Discussion}

This study examined the prevalence of anaemia and its risk factors among women attending $\mathrm{ANC}$ and PNC at the Hohoe Municipal Hospital, Ghana. The prevalence rate of anaemia among the ANC cohort was $33 \%$. This is slightly lower than the $38 \%$ global anaemia prevalence in pregnant women reported by [1]. A 2018 study by Kweku et al., found anaemia prevalence among women attending ANC at the same facility to be $60 \%$ [18]. The prevalence of this study points to a situation of moderate public health

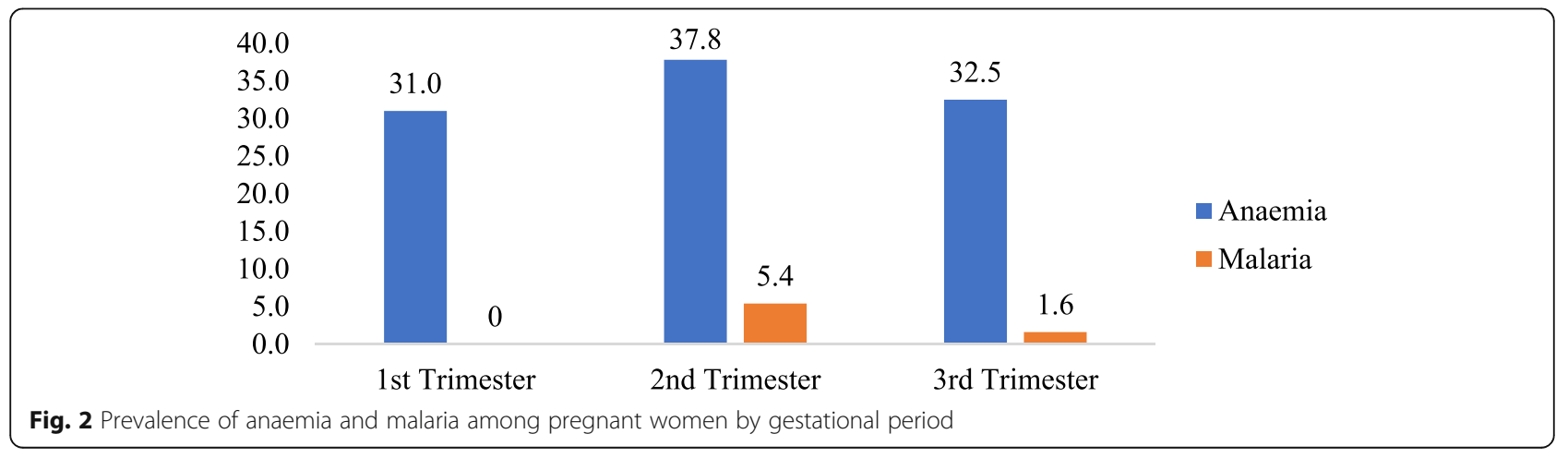




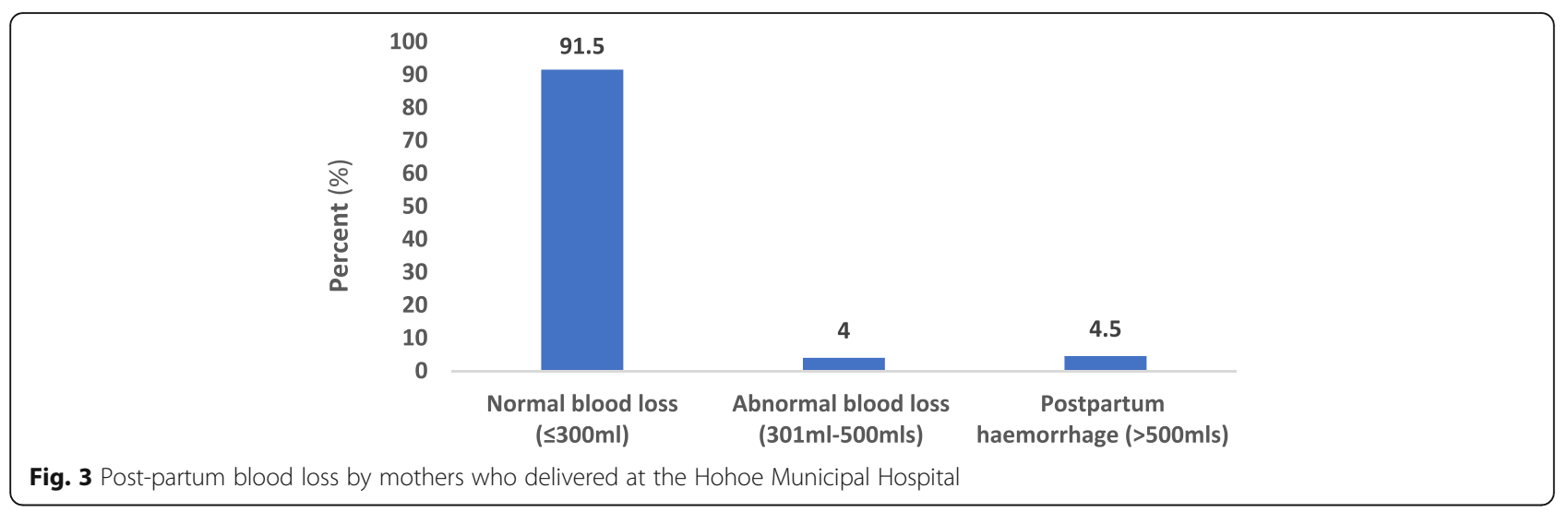

problem according to WHO cut-off values for the public health significance of anaemia. Based, on their findings, it was recommended that measures be instituted to address anaemia among pregnant women in the Municipality. As such, routine iron and folic acid supplementation to pregnant women was intensified at the facility, which could have played a significant role in the low prevalence of anaemia cases recorded in this study.

Interestingly, a similar study in 2016 by Bekele, Tilahun, \& Mekuria, [11] reported the same anaemia prevalence (33\%) among pregnant women in Ethiopia however, those recorded in South Africa (43\%) and Nigeria (55\%) among the same cohort were higher [26, 27].

However, our study further revealed that, anaemia prevalence among post-partum mothers attending postnatal care clinic was $16 \%$. This is lower than what was found in a study conducted among post-partum mothers in Ethiopia, 43\% [28] and also lower than that of a study among post-partum mothers in the southern region of Madrid, 29\% [29], an indication of the role iron and folic acid supplementation played as $73 \%$ of the post-partum cohort received them during pregnancy. Hence could account for the stark difference between the current study and that of [28], as no mention was made to iron and folic acid supplementation in their study. In addition, it could be due to the findings that a greater proportion of the postpartum women in our study are employed as a study by Lakew et al. in Ethiopia showed that working lactating mothers had a lower odds (AOR: $0.71 ; 95 \% \mathrm{CI}$ 0.63 to 0.80 ) of being anaemic. In the absence of other risk factors, postnatal mothers' age was associated with anaemia status in our study. However, a similar study by [30] found no significant association between mothers' age and anaemia status.

The current study provides information on anaemia among post-partum mothers as currently paucity of literature exits in the Volta Region and Ghana as a whole on post-natal anaemia. This information may help in future trend analysis of anaemia among postpartum mothers to identify the burden of this condition on the vulnerable population. In the year 2003, the Ghana Health Service (GHS) in collaboration with some stakeholders rolled out a five-year integrated strategy for anaemia control in Ghana which targeted pregnant women, pre-school and school-aged children [31]. However, the vulnerable group of post-natal mothers were not targeted in this strategy for anaemia control. Post-partum mothers, who undergo some physiological losses during child birth were not target in program and this could have been as result of paucity on post-partum anaemia as at the time the program was being rolled out by the GHS.

Malaria on the other hand was less prevalent (1\%) among post-partum mothers and insignificantly linked with anaemia in post-partum mothers. With fewer (62\%) mothers sleeping under insecticide treated mosquito nets and the few malaria cases were recorded, this can be attributed to some form of immunity developed against malaria by postpartum women. Thus, McLean and colleagues' study which showed a strong link between gravidity and antibodies development in improving their chances of not being anaemic [32] is evident. Therefore, the strong immunity against malaria could have been developed during pregnancy and maintained at post-partum period, fending off possible malaria attacks.

\section{Limitations}

Since data could not be collected throughout the year, seasonality of anaemia could not be ascertained. Moreover, data on HIV/AIDS status and on dietary diversity of respondents were not collected in the study which could have had an effect on the outcomes of the study. 
Table 2 Logistic regression of anaemia on socio-demographic characteristics in pregnant women [ $N=409]$

\begin{tabular}{|c|c|c|c|c|}
\hline \multirow{2}{*}{$\begin{array}{l}\text { Variables } \\
\text { Age group }\end{array}$} & \multicolumn{2}{|c|}{ Anaemia status } & \multirow[t]{2}{*}{ COR $(95 \% \mathrm{Cl})$} & \multirow[t]{2}{*}{$p$-value } \\
\hline & Normal n(\%) & Anaemic n(\%) & & \\
\hline $40+$ & $10(4)$ & $4(3)$ & Ref. & \\
\hline $30-39$ & $106(39)$ & $32(24)$ & $0.71(0.22,2.29)$ & 0.57 \\
\hline $20-29$ & $127(46)$ & $81(61)$ & $1.49(0.48,4.66)$ & 0.49 \\
\hline$<20$ & $32(11)$ & $17(12)$ & $1.25(0.36,4.37)$ & 0.72 \\
\hline \multicolumn{5}{|l|}{ Marital status } \\
\hline Single & $40(15)$ & $28(21)$ & Ref. & \\
\hline Married & $235(85)$ & $106(79)$ & $0.64(0.38,1.10)$ & 0.11 \\
\hline \multicolumn{5}{|l|}{ Religion } \\
\hline Christian & $235(86)$ & $111(83)$ & Ref. & \\
\hline Muslim & $40(14)$ & $23(17)$ & $1.22(0.70,2.13)$ & 0.49 \\
\hline \multicolumn{5}{|l|}{ Ethnicity } \\
\hline Ewe & $195(71)$ & $96(72)$ & & \\
\hline Other (Guan and Akan) & $80(29)$ & $38(28)$ & $0.96(0.61,1.52)$ & 0.88 \\
\hline \multicolumn{5}{|l|}{ Occupation } \\
\hline Unemployed & $65(24)$ & $37(28)$ & Ref. & \\
\hline Civil servant & $27(10)$ & $10(8)$ & $0.65(0.28,1.49)$ & 0.31 \\
\hline Farming & $11(4)$ & $4(2)$ & $0.63(0.19,2.15)$ & 0.47 \\
\hline Trading & $172(62)$ & $83(62)$ & $0.83(0.50,1.41)$ & 0.51 \\
\hline \multicolumn{5}{|l|}{ Gravidity } \\
\hline $1-2$ & $142(52)$ & $77(58)$ & Ref. & \\
\hline $3-5$ & $120(44)$ & $48(36)$ & $0.74(0.48,1.14)$ & \\
\hline $6+$ & $13(4)$ & $9(6)$ & $1.28(0.52,3.12)$ & 0.59 \\
\hline \multicolumn{5}{|l|}{ Parity } \\
\hline None & $92(34)$ & $52(39)$ & Ref. & \\
\hline $1-2$ & $116(42.2)$ & $52(39)$ & $0.79(0.49,1.27)$ & 0.34 \\
\hline $3+$ & $67(24.4)$ & $30(22)$ & $0.79(0.46,1.37)$ & 0.41 \\
\hline \multicolumn{5}{|l|}{ Blood film } \\
\hline Negative & $4(1)$ & $3(2)$ & Ref. & \\
\hline Positive & 271 (99) & $131(98)$ & $1.61(0.39,6.59)$ & 0.57 \\
\hline \multicolumn{5}{|l|}{ Gestational Age } \\
\hline 1st trimester & $40(15)$ & $18(13)$ & Ref. & \\
\hline 2nd trimester & $23(8)$ & $14(11)$ & $1.35(0.57,3.22)$ & 0.49 \\
\hline 3rd trimester & $212(77)$ & $102(76)$ & $1.06(0.58,1.96)$ & 0.82 \\
\hline \multicolumn{5}{|c|}{$\begin{array}{l}\text { Iron and folic acid supplementation } \\
\text { during pregnancy }\end{array}$} \\
\hline No & $37(13)$ & $19(14)$ & Ref. & \\
\hline Yes & $238(87)$ & $115(86)$ & $0.94(0.52,1.71)$ & 0.84 \\
\hline
\end{tabular}

\section{Conclusion}

Although the prevalence of anaemia among pregnant women found in this study was lower than the regional prevalence rate of women attending ANC (47\%), it still remains unacceptably high as it points to a situation of moderate public health problem according to WHO cutoff values for the public health significance of anaemia.
Age of mother has an association with anaemia in postpartum mothers in the Hohoe municipality, as younger mothers are more likely to be anaemic than older mothers. This could be due to insufficient interaction with health care providers as a result of infrequent visits by these women because of social stigma against young mothers who are unmarried. 
Table 3 Logistic regression of anaemia on socio-demographic characteristics in post-partum mothers [N=194]

\begin{tabular}{|c|c|c|c|c|}
\hline \multirow[t]{2}{*}{ Variables } & \multicolumn{2}{|c|}{ Anaemia status } & \multirow[b]{2}{*}{ COR $(95 \% \mathrm{Cl})$} & \multirow[b]{2}{*}{$p$-value } \\
\hline & Normal (\%) & Anaemia (\%) & & \\
\hline \multicolumn{5}{|l|}{ Age group } \\
\hline $40+$ & $10(6)$ & $0(0)$ & Ref. & \\
\hline $30-39$ & $46(28)$ & $12(38)$ & $0.60(0.23,1.57)$ & 0.30 \\
\hline $20-29$ & $86(52)$ & $10(31)$ & $0.27(0.103,0.72)$ & $0.008^{*}$ \\
\hline$<20$ & $23(14)$ & $10(31)$ & $0.11(0.01,1.99)$ & 0.13 \\
\hline \multicolumn{5}{|l|}{ Marital status } \\
\hline Single & $32(19)$ & $9(28)$ & Ref. & \\
\hline Married & $133(81)$ & $23(72)$ & $0.61(0.26,1.46)$ & 0.27 \\
\hline \multicolumn{5}{|l|}{ Religion } \\
\hline Christian & $138(84)$ & $29(91)$ & Ref. & \\
\hline Muslim & $27(16)$ & $3(9)$ & $0.53(0.15,1.86)$ & 0.32 \\
\hline \multicolumn{5}{|l|}{ Tribe } \\
\hline Ewe & $125(76)$ & $23(72)$ & Ref. & \\
\hline Other (Guan and Akan) & $40(24)$ & $9(28)$ & $1.22(0.52,2.85)$ & 0.64 \\
\hline \multicolumn{5}{|l|}{ Parity } \\
\hline $1-2$ & $97(59)$ & $21(66)$ & Ref. & \\
\hline $3+$ & $68(41)$ & $11(34)$ & $0.76(0.33,1.66)$ & 0.49 \\
\hline \multicolumn{5}{|l|}{ Blood film } \\
\hline Negative & $163(99)$ & $32(100)$ & Ref. & \\
\hline Positive & $2(1)$ & $0(0)$ & $1.01(0.05,21.45)$ & 0.99 \\
\hline \multicolumn{5}{|l|}{ Gravidity } \\
\hline $1-2$ & $97(59)$ & $19(59)$ & Ref. & \\
\hline $3-5$ & $56(34)$ & $10(32)$ & $0.91(0.40,2.10)$ & 0.83 \\
\hline $6+$ & $12(7)$ & $3(9)$ & $1.28(0.32,4.96)$ & 0.73 \\
\hline \multicolumn{5}{|c|}{ Estimated blood loss $(n=177)$} \\
\hline Normal & $139(94)$ & $23(82)$ & Ref. & \\
\hline Abnormal & $5(3)$ & $2(7)$ & $2.42(0.44,13.20)$ & 0.31 \\
\hline $\mathrm{PPH}$ & $5(3)$ & $3(11)$ & $3.63(0.81,16.22)$ & 0.09 \\
\hline \multicolumn{5}{|c|}{ Iron and folic acid supplementation during pregnancy } \\
\hline No & $44(27)$ & $7(22)$ & Ref. & \\
\hline Yes & $121(73)$ & $25(78)$ & $1.39(0.07,27.76)$ & 0.83 \\
\hline \multicolumn{5}{|l|}{ Mosquito Net Usage } \\
\hline No & $102(62)$ & $19(59)$ & Ref. & \\
\hline Yes & $63(38)$ & $13(41)$ & $0.89(0.42,1.92)$ & 0.78 \\
\hline
\end{tabular}

Strategies should therefore be put in place to encourage frequent postnatal visits by women in the younger age group. Measures must also be put in place to adopt programmes to address abnormal blood loss and PPH. This could be achieved through health education and promotion programmes. Further studies however need to be done to establish the causal effect relationship between anaemia and these risk factors in the Municipality.

\section{Abbreviations}

ANC: Antenatal care; COR: Crude odds ratio; ERC: Ethical Review Committee; FDH: Family health division; GHS: Ghana Health Service; Hb: Haemoglobin; ICH/GCP: International conference on Harmonization/Good Clinical Practice; PNC: Postnatal care; PPH: Postpartum haemorrhage; SPH: School of Public health; UHAS: University of Health and Allied Sciences; WBC: White blood cells; WHO: World Health Organization

\section{Acknowledgements}

We are grateful to the staff of the School of Public Health Research Laboratory, University of Health and Allied Sciences. We are also grateful to 
Dr. Pius Mensah and the staff of the Hohoe Municipal Hospital. We would like to thank the interviewers as well as the pregnant women and postpartum mothers who participated in the study.

\section{Authors' contributions}

PK, EET, and MK conceived the study. PK, MA, and MK did the data analysis and wrote the methods section. PK, EET, EM, HA, MAA, FYA, JK, MA, FB, and $M K$, were responsible for the initial draft of the manuscript. All authors reviewed and approved the final version of the manuscript.

\section{Funding}

Not applicable.

\section{Availability of data and materials}

The datasets used or analysed during the current study are available from the corresponding author on reasonable request.

\section{Ethics approval and consent to participate}

This study was conducted in accordance with accepted principles on ethics in human experimentation and international conference on Harmonization/ Good Clinical Practice (ICH/GCP). Ethical approval for the study was obtained from the Ethics Review Committee (ERC) of the University of Health and Allied Sciences (UHAS) with Ethical Approval number UHAS-ERC A.6 [6] 1718. Permission was sought from the Hohoe Municipal Hospital before the commencement of the study. Written informed consent was obtained from participants on standard consent form before they were included in the study. Minors were not involved in the study.

\section{Consent for publication}

Not applicable.

\section{Competing interests}

The authors declare that they have no competing interests.

\section{Author details}

'Department of Epidemiology and Biostatistics, School of Public Health, University of Health and Allied Sciences, PMB 31, Ho, Volta Region, Ghana. ${ }^{2}$ Department of Population and Behavioural Sciences, School of Public Health, University of Health and Allied Sciences, PMB 31, Ho, Volta Region, Ghana. ${ }^{3}$ Department of Family and Community Health, University of Health and Allied Sciences, PMB 31, Ho, Volta Region, Ghana.

\section{Received: 25 March 2019 Accepted: 11 July 2019}

\section{Published online: 23 September 2019}

\section{References}

1. World Health Organization. The global prevalence of anaemia in 2011 Download from: https://www.who.int/nutrition/publications/micronutrients/ global_prevalence_anaemia_2011/en/.Pdf. 2015.

2. World Health Organization. Haemoglobin concentrations for the diagnosis of anaemia and assessment of severity. 2011. Download from: http://www. who. int/vmnis/indicators/haemoglobin. pdf. 2015.

3. Pavord S, Myers B, Robinson S, Allard S, Strong J, Oppenheimer C. British Committee for Standards in Haematology. UK guidelines on the management of iron deficiency in pregnancy. Br J Haematol. 2012;156(5):588-600.

4. Obai G, Odongo P, Wanyama R. Prevalence of anaemia and associated risk factors among pregnant women attending antenatal care in Gulu and Hoima regional hospitals in Uganda: a cross sectional study. BMC Pregnancy Childbirth. 2016;16(1):76.

5. MacDonald C, Mildon A, Neequaye M, Namarika R, Yiannakis M. Anemiacan its widespread prevalence among women in developing countries be impacted? A case study: effectiveness of a large-scale, integrated, multipleintervention nutrition program on decreasing anemia in Ghanaian and Malawian women. In: Women's health in the majority world: issues and initiatives. New York: Nova Science Publishers Inc.; 2007. p. 65-107.

6. Camaschella C. Iron-deficiency anemia. N Engl J Med. 2015;372(19):1832-43.

7. Melku M, Addis Z, Alem M, Enawgaw B. Prevalence and predictors of maternal anemia during pregnancy in Gondar, Northwest Ethiopia: an institutional based cross-sectional study. Anemia. 2014;2014.
8. Suryanarayana R, Santhuram AN, Chandrappa M, Shivajirao P, Rangappa SS. Prevalence of anaemia among pregnant women in rural population of Kolar district. Int J Med Sci Public Health. 2016;5(3):454-8.

9. Cox AJ. The effects of Iron deficiency Anemia and Iron supplementation in pregnancy.2016.http://digitalcommons.liberty.edu/cgi/viewcontent. cgi?article=1628\&context=honors. Accessed 2 Apr 2018.

10. Gambling L, Kennedy C, McArdle HJ. Iron and copper in fetal development. Semin Cell Dev Biol. 2011;22(6):637-44 Academic Press.

11. Alem M, Enawgaw B, Gelaw A, Kena T, Seid M, Olkeba Y. Prevalence of anemia and associated risk factors among pregnant women attending antenatal care in Azezo health center Gondar town, Northwest Ethiopia. J Interdiscipl Histopathol. 2013;1(3):137-44.

12. Bekele A, Tilahun M, Mekuria A. Prevalence of anemia and its associated factors among pregnant women attending antenatal care in health institutions of Arba Minch town, Gamo Gofa zone, Ethiopia: a crosssectional study. Anemia. 2016;2016.

13. Lakew $Y$, Biadgilign $S$, Haile D. Anaemia prevalence and associated factors among lactating mothers in Ethiopia: evidence from the 2005 and 2011 demographic and health surveys. BMJ Open. 2015;5(4):e006001.

14. FHD. Family Health Division Annual Report 2016. 2016. http://www. ghanahealthservice.org/downloads/FHD_2016_ANNUAL_REPORT_Final_ June\%2019.2017\%20nat\%20final.pdf. Accessed 23 Jan 2018.

15. GDHS. Ghana Demographic Health Survey. 2014. https://dhsprogram.com/ pubs/pdf/fr307/fr307.pdf. Accessed 4 Jan 2018.

16. Duodu F. Anaemia kills 37 in Volta. Daily guide; 2017.

17. Anane M. Anaemia; leading cause of death in Volta region. Graphic online; 2015.

18. Kweku M, Ofori M, Takramah W, Axame WK, Owusu R, Parbey P, Adjuik M, Tarkang E. Prevalenceof malaria and anaemiaamong pregnant women attending antenatal Care Clinic in the Hohoe Municipality of Ghana. Int J Nurs Didactics. 2017;7(7):21-30.

19. Ghana Statistical Service. District census report. 2016. http://www2. statsghana.gov.gh/docfiles/2010_District_Report/Nolta/Hohoe\%20Mun.pdf. Acessed 4 Jan 2018

21. Cochran WG. Sampling techniques-3; 1977.

20. Milman N. Postpartum anemia I: definition, prevalence, causes, and consequences. Ann Hematol. 2011;90(11):1247.

22. Ahmad NA, Awaluddin SM, Samad R, Kasim NM, Yusof M, Razak M, et al. Validity of point-of-care testing mission plus in detecting anemia. Int J Biomed. 2015;5:91-4.

23. Simmonds MJ, Baskurt OK, Meiselman HJ, Marshall-Gradisnik SM. A comparison of capillary and venous blood sampling methods for the use in haemorheology studies. Clin Hemorheol Microcirc. 2011;47(2):111-9.

24. Houwen B. Blood film preparation and staining procedures. Lab Hematol. 2000;6:1-7.

25. Tunkyi K, Moodley J. Prevalence of anaemia in pregnancy in a regional health facility in South Africa. S Afr Med J. 2016;106(1):101-4.

26. Olatunbosun OA, Abasiattai AM, Bassey EA, James RS, Ibanga G, Morgan A. Prevalence of anaemia among pregnant women at booking in the University of Uyo Teaching Hospital, Uyo, Nigeria. Biomed Res Int. 2014;2014.

27. Feleke BE, Feleke TE. Pregnant mothers are more anemic than lactating mothers, a comparative cross-sectional study, Bahir Dar, Ethiopia. BMC Hematol. 2018;18(1):2.

28. Medina Garrido C, León J, Romaní Vidal A. Maternal anaemia after delivery: prevalence and risk factors. J Obstet Gynaecol. 2018;38(1):55-9.

31. McLean AR, Ataide R, Simpson JA, Beeson JG, Fowkes FJ. Malaria and immunity during pregnancy and postpartum: a tale of two species. Parasitology. 2015;142(8):999-1015.

29. Bhagwan D, Kumar A, Rao CR, Kamath A. Prevalence of Anaemia among postnatal mothers in coastal Karnataka. J Clin Diagn Res. 2016;10(1):LC17.

30. SPRING, Ghana Health Service. Ghana: Landscape Analysis of Anemia and Anemia Programming. Arlington: Strengthening Partnerships, Results, and Innovations in Nutrition Globally (SPRING) project; 2016.

32. Boghani S, Mei Z, Perry G, Brittenham G, Cogswell M. Accuracy of capillary hemoglobin measurements for the detection of anemia among US lowincome toddlers and pregnant women. Nutrients. 2017;9(3):253.

\section{Publisher's Note}

Springer Nature remains neutral with regard to jurisdictional claims in published maps and institutional affiliations. 